\title{
Article \\ Molecular Docking Studies and Biological Evaluation of Berberine-Benzothiazole Derivatives as an Anti-Influenza Agent via Blocking of Neuraminidase
}

\author{
Manu Kumar ${ }^{1}$ (D), Sang-Min Chung ${ }^{1}$, Ganuskh Enkhtaivan ${ }^{2}$, Rahul V. Patel ${ }^{3}$, Han-Seung Shin ${ }^{3}$ \\ and Bhupendra M. Mistry ${ }^{3, *}$
}

1 Department of Life Science, Dongguk University-Seoul, Ilsandong-gu, Goyang-si, Gyeonggi-do 10326, Korea; manukumar007@gmail.com (M.K.); smchung@dongguk.edu (S.-M.C.)

2 Department of Bio-resources and Food Science, Konkuk University, Seoul 143-701, Korea; enkhtaivan11@naver.com

3 Department of Food Science and Biotechnology, Dongguk University-Seoul, Ilsandong-gu, Goyang-si, Gyeonggi-do 410-820, Korea; rahul.svnit11@gmail.com (R.V.P.); spartan@dongguk.edu (H.-S.S.)

* Correspondence: bhupendra.mistry84@gmail.com; Tel.: +82-31-961-5616

check for

updates

Citation: Kumar, M.; Chung, S.-M.; Enkhtaivan, G.; Patel, R.V.; Shin,

H.-S.; Mistry, B.M. Molecular Docking Studies and Biological Evaluation of Berberine-Benzothiazole Derivatives as an Anti-Influenza Agent via Blocking of Neuraminidase. Int. J. Mol. Sci. 2021, 22, 2368. https:// doi.org/10.3390/ijms22052368

Academic Editor: Piotr Dobrzynski

Received: 29 January 2021

Accepted: 23 February 2021

Published: 27 February 2021

Publisher's Note: MDPI stays neutral with regard to jurisdictional claims in published maps and institutional affiliations.

Copyright: (c) 2021 by the authors. Licensee MDPI, Basel, Switzerland. This article is an open access article distributed under the terms and conditions of the Creative Commons Attribution (CC BY) license (https:// creativecommons.org/licenses/by/ $4.0 /)$.

\begin{abstract}
In this study, we have introduced newly synthesized substituted benzothiazole based berberine derivatives that have been analyzed for their in vitro and in silico biological properties. The activity towards various kinds of influenza virus strains by employing the cytopathic effect (CPE) and sulforhodamine B (SRB) assay. Several berberine-benzothiazole derivatives (BBDs), such as BBD1, BBD3, BBD4, BBD5, BBD7, and BBD11, demonstrated interesting anti-influenza virus activity on influenza A viruses (A/PR/8/34, A/Vic/3/75) and influenza B viral (B/Lee/40, and $\mathrm{B} /$ Maryland/1/59) strain, respectively. Furthermore, by testing neuraminidase activity (NA) with the neuraminidase assay kit, it was identified that BBD7 has potent neuraminidase activity. The molecular docking analysis further suggests that the BBD1-BBD14 compounds' antiviral activity may be because of interaction with residues of NA, and the same as in oseltamivir.
\end{abstract}

Keywords: neuraminidase assay; antiviral activity; molecular docking; SRB assay

\section{Introduction}

The extremely pathogenic influenza is probably the most commonly infected, severe respiration disease occurring seasonally in most countries. It remains a lethal disease due to the high rate of deaths caused by it. In most cases, high mortality rates in resource-limited nations are due to an insufficient supply of pharmaceutical drugs [1,2]. Influenza continues to be a severe health issue, and because of this infection, people of all ages consistently suffer. This pandemic respiratory disease might begin mainly by two essential mechanisms: transmission mechanism from birds to humans or genetic reassortment involving avian respiratory disease and human influenza viruses. Leading documented influenza were H7N9 (bird flu) of 2013, 2009 H1N1 (swine flu), 2005 H5N1 (bird flu), 1968 H3N2 (Hong Kong flu), 1957 H2N2 (Asian flu), and 1918 H1N1 (Spanish flu) [3-6]. Every year these epidemics are the leading causes of three to five million sicknesses and about 290,000 to 650,000 deaths worldwide [7].

Neuraminidase (NA), also referred to as sialidase, is the essential surface glycoprotein of the influenza virus that performs a vital and unique role in the influenza virus life cycle. It provides relief from virus progression. It is an essential enzyme in the infestation, maturity, replication, and distribution of the influenza virus [8-10]. There are currently two primary approaches available against the virus: small molecule anti-influenza drugs and vaccines. Oseltamivir and zanamivir are the two commercially potent NA inhibitors that cure influenza A and B infections [11,12]. 
Berberine, a plant-derived isoquinoline organic compound, having a protracted history of therapeutic use in Chinese drugs and Ayurveda. It belongs to Ranunculaceae, Papaveraceae, and Berberidaceae families. It is isolated from Berberis vulgaris, Berberis petiolaris, Berberis aristata, Berberis asiatica, Berberis thunbergii, Berberis aquifolium, Coptis chinensis, Coptis teeta, Caulis mahoniae, Hydrastis canadensis, and Phellodendron amurense. Berberine has significant actions towards antiviral activity [13-16], antidiarrheal effect [17], hypotensive effect [18], antibacterial effect [19], nuclear factor kappa-light-chain-enhancer of activated B (NF-kB) pathway [14], epidermal growth factor receptor (EGFR)/ mitogenactivated protein kinase kinase (MEK) / extracellular-signal-regulated kinase (ERK) signal pathway [20], and AMPK/mTOR signal pathway [21].

Our study aims to produce a resistance-free antiviral drug. For that, we identified the potential effects of berberine-benzothiazole derivatives (BBDs) on the influenza virus and their active target site on the influenza virus by in vitro and in silico analysis. In this study, we examined BBDs for their anti-influenza action towards numerous strains of influenza virus employing CPE reduction screening with the SRB methodology. We found out that our newly synthesized BBDs exhibited a potent antiviral activity towards the influenza virus and collectively blocked viral NA activity. Furthermore, we have also applied a molecular docking study to evaluate the ligand-virus interactions of BBDs. To analyze the influence of binding ability of BBDs with the virus, the substituted BBDs, and the oseltamivir have been docked into the NA active site and their binding energies analyzed.

\section{Results and Discussion}

\subsection{Cytotoxicity and Anti-Influenza Activity}

Antiviral activity of the titled scaffolds BBD1-BBD14 was examined by applying an in vitro sulforhodamine $B(\mathrm{SRB})$ bioassay. The final results were presented in Table 1 . In the CPE method, various influenza viral strains $(\mathrm{A} / \mathrm{PR} / 34 / 8, \mathrm{~A} / \mathrm{Vic} / 3 / 75, \mathrm{~B} / \mathrm{Lee} / 40$, and B/Maryland /1/59) were used with Madin-Darby Canine Kidney (MDCK) cells along with commercial drug oseltamivir as positive control drugs. The focus of the existing research was to improve the antiviral efficiency of berberine-benzothiazole components favorably through its well-rationalized derivatization, which is sufficient to discuss here that all title compounds revealed more significant antiviral results with half-maximal inhibitory concentrations (IC50s) varying from $24.28 \pm 0.419-68.02 \pm 0.670 \mu \mathrm{g} / \mathrm{mL}, 38.81 \pm 2.51-70.65 \pm 0.94$, $36.94 \pm 1.52-85.12 \pm 3.74$, and $36.88 \pm 2.15-98.33 \pm 2.21$ towards influenza virus A/PR/34/8, A/Vic/3/75, B/Lee/40, and B/Maryland/1/59 strain. Antiviral analogs should not be cytotoxic towards the healthier cells; thus, the cytotoxicity levels of titled compounds towards MDCK cell lines are crucial. Presented CC50s in the variety $45.1 \pm 0.864-467.7 \pm 2.647 \mu \mathrm{g} / \mathrm{mL}$, which was throughout the bearable and therefore provided outstanding therapeutic indices (TI) of 4.835-19.08 (A/PR/34/8), 3.663-11.94 (A/Vic/3/75), 4.327-8.294 (B/Lee/40), and 3.851-7.924 (B/Maryland/1/59) respectively. Further, the existence of the electron-donating (ED) or electron-withdrawing (EWD) functional groups on the benzothiazole ring resulted in the molecules presenting a variable degree of antiviral effects. The most potent berberinebenzothiazole derivatives against the influenza virus $\mathrm{A} / \mathrm{PR} / 34 / 8$ strain within the series tested was BBD7 with a chloro, benzothiazole functionalities attached to the berberine core analogue. Among all tested with $24.28 \pm 0.419 \mu \mathrm{g} / \mathrm{mL}$ of IC50 and $463.5 \pm 3.386 \mu \mathrm{g} / \mathrm{mL}$ of CC50 with most active TI of 19.08 when compared to its parent's molecule berberine $36.12 \pm 1.57 \mu \mathrm{g} / \mathrm{mL}$ of IC50 and $65.34 \pm 1.92 \mu \mathrm{g} / \mathrm{mL}$ of CC50 and TI of 1.808 . The oseltamivir control drug showed moderate activity (11.56 \pm 1.43 of IC50, $205.3 \pm 1.78$ of CC50, and TI of 17.75). However, it can be noted that two other analogues appeared to have high antiviral efficacies as unsubstituted BBD1 and di-fluoro (BBD11) benzothiazole functionalities displayed $25.20 \pm 0.154 \mu \mathrm{g} / \mathrm{mL}$ and $27.20 \pm 0.394$ of IC50 values and 17.32 and 17.19 of TIs, respectively. They had lower cytotoxic values of $436.7 \pm 2.635 \mu \mathrm{g} / \mathrm{mL}$ and $467.7 \pm 2.647 \mu \mathrm{g} / \mathrm{mL}$, respectively. 
Table 1. In vitro optimization of berberine-benzothiazole-based inhibitors.

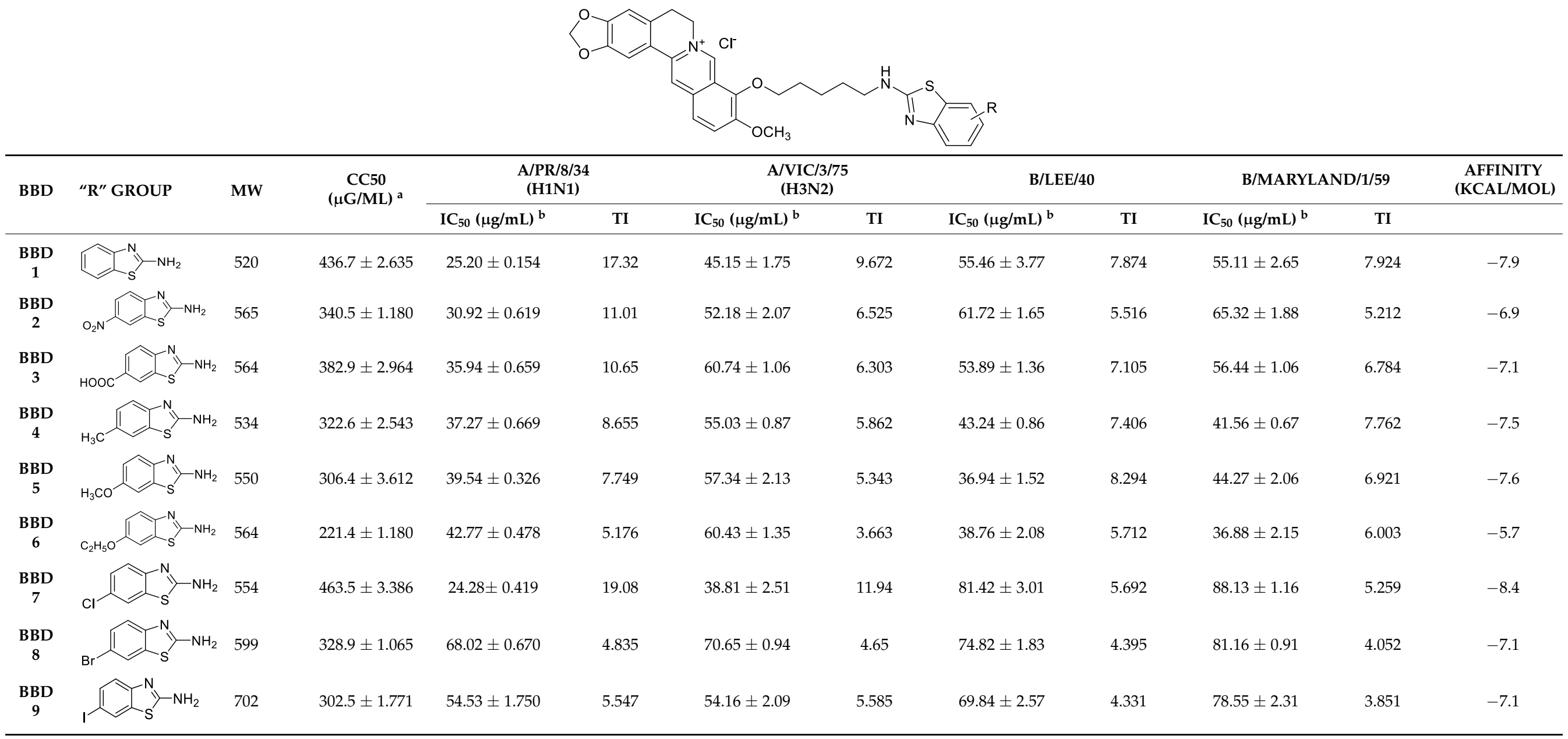


Table 1. Cont.

\begin{tabular}{|c|c|c|c|c|c|c|c|c|c|c|c|c|}
\hline \multirow[t]{2}{*}{ BBD } & \multirow[t]{2}{*}{ "R" GROUP } & \multirow[t]{2}{*}{ MW } & \multirow{2}{*}{$\begin{array}{c}\text { CC50 } \\
(\mu \mathrm{G} / \mathrm{ML})^{\mathrm{a}}\end{array}$} & \multicolumn{2}{|c|}{$\begin{array}{c}\text { A/PR/8/34 } \\
\text { (H1N1) }\end{array}$} & \multicolumn{2}{|c|}{$\begin{array}{c}\text { A/VIC/3/75 } \\
\text { (H3N2) }\end{array}$} & \multicolumn{2}{|c|}{ B/LEE/40 } & \multicolumn{2}{|c|}{ B/MARYLAND/1/59 } & \multirow[t]{2}{*}{$\begin{array}{c}\text { AFFINITY } \\
\text { (KCAL/MOL) }\end{array}$} \\
\hline & & & & $\mathrm{IC}_{50}(\mu \mathrm{g} / \mathrm{mL})^{\mathrm{b}}$ & TI & $\mathrm{IC}_{50}(\mu \mathrm{g} / \mathrm{mL})^{\mathrm{b}}$ & TI & $\mathrm{IC}_{50}(\mu \mathrm{g} / \mathrm{mL})^{\mathrm{b}}$ & TI & $\mathrm{IC}_{50}(\mu \mathrm{g} / \mathrm{mL})^{\mathrm{b}}$ & TI & \\
\hline $\begin{array}{c}\text { BBD } \\
10\end{array}$ & & 539 & $310.6 \pm 1.629$ & $30.50 \pm 0.761$ & 10.18 & $49.87 \pm 1.31$ & 6.228 & $64.64 \pm 1.24$ & 4.812 & $75.74 \pm 2.06$ & 4.100 & -6.8 \\
\hline $\begin{array}{c}\text { BBD } \\
11\end{array}$ & & 556 & $467.7 \pm 2.647$ & $27.20 \pm 0.394$ & 17.19 & $48.44 \pm 2.20$ & 9.655 & $85.12 \pm 3.74$ & 5.494 & $98.33 \pm 2.21$ & 4.75 & -8.0 \\
\hline $\begin{array}{c}\text { BBD } \\
12\end{array}$ & & 588 & $302.3 \pm 2.446$ & $28.73 \pm 0.514$ & 10.52 & $44.56 \pm 1.65$ & 6.784 & $67.65 \pm 1.52$ & 4.468 & $66.22 \pm 1.82$ & 4.565 & -6.0 \\
\hline $\begin{array}{l}\text { BBD } \\
13\end{array}$ & & 545 & $45.1 \pm 0.864$ & ND & - & ND & - & ND & - & ND & - & -6.7 \\
\hline $\begin{array}{c}\text { BBD } \\
14\end{array}$ & & 591 & $304.3 \pm 1.261$ & $40.34 \pm 0.725$ & 7.543 & $56.32 \pm 2.06$ & 5.403 & $70.32 \pm 2.24$ & 4.327 & $73.44 \pm 2.17$ & 4.143 & -6.7 \\
\hline & $\begin{array}{l}\text { RBERINE } \\
\text { LTAMIVIR }\end{array}$ & & $\begin{array}{l}65.34 \pm 1.92 \\
205.3 \pm 1.78\end{array}$ & $\begin{array}{l}36.12 \pm 1.57 \\
11.56 \pm 1.43\end{array}$ & $\begin{array}{l}1.808 \\
17.75\end{array}$ & $\begin{array}{l}41.58 \pm 2.04 \\
22.14 \pm 1.07\end{array}$ & $\begin{array}{l}1.571 \\
9.27\end{array}$ & $\begin{array}{l}60.83 \pm 1.86 \\
55.87 \pm 1.13\end{array}$ & $\begin{array}{l}1.07 \\
3.67\end{array}$ & $\begin{array}{l}54.63 \pm 1.45 \\
44.17 \pm 1.83\end{array}$ & $\begin{array}{c}1.196 \\
4.64\end{array}$ & - \\
\hline
\end{tabular}

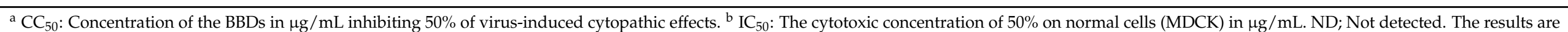
the mean of standard deviation $\left( \pm S\right.$.D) in triplicate. TI: Therapeutic index $\left(\mathrm{TI}=\mathrm{CC}_{50} / \mathrm{IC}_{50}\right)$. 
With fact that the presence of a strong electron-withdrawing nitro group in BBD2 (IC50: $30.92 \pm 0.619 \mu \mathrm{g} / \mathrm{mL}$, CC50: $340.5 \pm 1.180 \mu \mathrm{g} / \mathrm{mL}$ and TI: 11.01 ), BBD12 with trifluoromethyl group (IC50: $28.73 \pm 0.514 \mu \mathrm{g} / \mathrm{mL}$, CC50: $302.3 \pm 2.446 \mu \mathrm{g} / \mathrm{mL}$ and TI: 10.52), BBD10 with fluoro group (IC50: $30.50 \pm 0.761 \mu \mathrm{g} / \mathrm{mL}$, CC50: $310.6 \pm 1.629 \mu \mathrm{g} / \mathrm{mL}$ and TI: 10.18), and acid group in BBD3 (IC50: $35.94 \pm 0.659 \mu \mathrm{g} / \mathrm{mL}$, CC50: $382.9 \pm 2.964 \mu \mathrm{g} / \mathrm{mL}$ and TI: 10.65), made up interesting efficacy against influenza virus $\mathrm{A} / \mathrm{PR} / 34 / 8$ strain, respectively compared to those existing methyl (BBD4; IC50: $37.27 \pm 0.669 \mu \mathrm{g} / \mathrm{mL}$, CC50: $322.6 \pm 2.543 \mu \mathrm{g} / \mathrm{mL}$ and TI: 8.655), methoxy (BBD5; IC50: $39.54 \pm 0.326 \mu \mathrm{g} / \mathrm{mL}$, CC50: $306.4 \pm 3.612 \mu \mathrm{g} / \mathrm{mL}$ and TI: 7.749), ethoxy (BBD6; IC50: $42.77 \pm 0.478 \mu \mathrm{g} / \mathrm{mL}$, CC50: $221.4 \pm 1.180 \mu \mathrm{g} / \mathrm{mL}$ and TI: 5.176), bromo group (BBD8; IC50: $68.02 \pm 0.670 \mu \mathrm{g} / \mathrm{mL}$, CC50: $328.9 \pm 1.065 \mu \mathrm{g} / \mathrm{mL}$ and TI: 4.835), Iodo group (BBD9; IC50: $54.53 \pm 1.750 \mu \mathrm{g} / \mathrm{mL}$, CC50: $302.5 \pm 1.771 \mu \mathrm{g} / \mathrm{mL}$ and TI: 5.547) and hydrazinobenzthaizole (BBD14; IC50: $40.34 \pm 0.725 \mu \mathrm{g} / \mathrm{mL}, \mathrm{CC} 50: 304.3 \pm 1.261 \mu \mathrm{g} / \mathrm{mL}$ and TI: 7.543). All the compounds were more active than its parent berberine molecule in terms of TI values.

In the bioassay A/Vic/3/75 strain against derivative BBD7 having an EWD chlorine group demonstrated remarkable $38.81 \pm 2.51$ of IC50 with 11.94 of TI followed by an analogue BBD1 with $45.15 \pm 1.75$ of IC50 with 9.672 of TI and an analogue with 2,4-difluoro functionality in BBD11 with $48.44 \pm 2.20$ of IC50 with 9.655 of TI, respectively. These IC50 and TI values are far better than their parent berberine molecule, and TI values were similar to the control drug oseltamivir. Furthermore, in halogenated analogues, within the case of $\mathrm{F}$ and $\mathrm{Cl}$ having molecules (BBD7, BBD10, BBD11, and BBD12) observed higher antiviral effects than with $\mathrm{Br}$ and I containing molecules. Hence, forming the antiviral activity order of $\mathrm{Cl}>\mathrm{F}>\mathrm{I}>\mathrm{Br}$ within halogenated groups. Among analogues, those carrying BBD3 with an acid group were found to have moderate antiviral activity, and ED groups like methyl, methoxy, and ethoxy functionality, also displayed moderated activity compared to control drug oseltamivir. However, when compared to berberine molecules, it showed potent activity in terms of TI values. A compound BBD2 with the nitro group and BBD14 without any substitution display a considerable level of antiviral action with $52.18 \pm 2.07$ of IC50 with 6.525 of TI, and $56.32 \pm 2.06$ of IC50 with 5.403 of TI, respectively, which is higher than the parental berberine molecule in terms of TI values. A compound BBD5 with an ED methoxy group attached to berberine core via alkyl chain was most active among all those studied against B/Lee/40 strain with $36.94 \pm 1.52$ of IC50 with 8.294 of TI, which was higher than berberine (60.83 \pm 1.86 of IC50, 1.07 of TI) and control drug Oseltamivir (55.87 \pm 1.13 of IC50, 3.67 of TI). Besides another unsubstituted analogue BBD1, BBD4 with ED methyl group and BBD3 with an acid group showed the highest level of B/Lee/40 strain inhibition potential comparable to that of control drug oseltamivir with $55.46 \pm 3.77$ of IC50 with 7.874 of TI, and $43.24 \pm 0.86$ of IC50 with 7.406 of TI, and $53.89 \pm 1.36$ of IC50 with 7.105 of TI, respectively. The data revealed that BBD5 (36.94 \pm 1.52 of IC50, TI: 8.294) with methoxy group was more active than BBD6 (38.76 \pm 2.08 of IC50, TI: 5.712) with an ethoxy group, which was closest to the control drug, oseltamivir, in value and was far better than the parent berberine molecule.

A compound EWD halo atom(s) demonstrated a remarkable structure-activity relationship as BBD7 with chlorine group having $81.42 \pm 3.01$ of IC50 with 7.105 of TI followed by BBD11 with di-fluoro (85.12 \pm 3.74 of IC50 TI: 5.494), BBD10 with fluoro (64.64 \pm 1.24 of IC50 TI: 4.812$)$ and BBD12 with trifluoro functionalities (67.65 \pm 1.52 of IC50 TI: 4.468), respectively. A compound BBD8 (74.82 \pm 1.83 of IC50 TI: 4.395) with a Bromo group and BBD9 (69.84 \pm 2.57 of IC50 TI: 4.331) with an iodo group were less active in halogenated groups. A compound BBD2 with the nitro group and BBD14 with an unsubstituted group displayed promising antiviral activity against B/Lee/40 strain. Overall, all the compounds exhibited more activity than the control drug oseltamivir and far better than parent berberine molecules.

Finally, an analogue without any substation BBD1 furnished a remarkable antiviral inhibitory efficacy level with $55.11 \pm 2.65$ of IC50 with 7.924 of TI against B/Maryland /1/59 strain, which was more active than control drug oseltamivir and much better than berberine. 
Furthermore, the functionality of compounds with ED groups of a BBD4-bearing methyl group, BBD5-bearing methoxy group, BBD6-bearing ethoxy group, had an appreciable level of antiviral activity against the B/Maryland/1/59 strain with $41.56 \pm 0.67$ of IC50 with 7.762 of TI, $44.27 \pm 2.06$ of IC50 with 6.921 of TI, and $36.88 \pm 2.15$ of IC50 with 6.003 of TI, respectively. Moreover, the presence of EWD halogenated groups such as chlorine (BBD7), fluorine (BBD10), difluoro (BBD11), trifluoromethane (BBD12), bromine (BBD8) and iodine (BBD9) groups connected to the berberine core and was effective for B/Maryland/1/59 strain with $88.13 \pm 1.16$ of IC50 with 5.259 of TI, $75.74 \pm 2.06$ of IC50 with 4.100 of TI, $98.33 \pm 2.21$ of IC50 with 4.75 of TI, $66.22 \pm 1.82$ of IC50 with 4.565 of TI, $81.16 \pm 0.91$ of IC50 with 4.052 of TI, and $78.55 \pm 2.31$ of IC50 with 3.851 of TI, respectively.

The existence of two fluorine atoms enhanced the antiviral effect of BBD11 is in contrast with that of its mono-substituted fluorine atom BBD10. Furthermore, an analogue BBD2-bearing nitro group, BBD3-bearing acid group, and BBD14 without substitution had a remarkable antiviral activity against the B/Maryland/1/59 strain with $65.32 \pm 1.88$ of IC50 with 5.212 of TI, $56.44 \pm 1.06$ of IC50 with 6.784 of TI, and $73.44 \pm 2.17$ of IC50 with 4.143 of $\mathrm{TI}$, respectively. Overall, the analogues showed active property against the B/Maryland/1/59 strain compared to the control drug oseltamivir and much better than the parent berberine molecule. The cyano group (BBD13) did not show any activity towards any influenza virus strains. Besides, previous research revealed that berberine and its derivatives confirmed strong anti-influenza activity via blocking of activity of influenza NA $[14,15]$. Therefore, we tested BBDs for inhibition of influenza NA activity via NA inhibition assay.

\subsection{NA Inhibition Activity of BBDs}

The NA of influenza virus is popularly known as sialidase. It consists of four similar subunits and attached to the membrane of the virus. NA, performs an essential role in the multiplication of the virus. The glycoproteins from neuraminic acid residues were recently found to have virion progeny type glycosidic linkage with the neuraminic acid receptor around the host-cell surface area; this glycosidic connection is divided by NA, which permits within the discharge from the virion progeny through the infected cells. Along these lines, NA is an alluring objective for anti-influenza research [22,23]. At present, three NA inhibitors have been widely used as anti-influenza drug-like zanamivir, oseltamivir, and peramivir. The protein action is also responsible for stopping the self-aggregation of virus particles by cleavage of sialic acids still certain towards the infection surface. We, subsequently, tried the potential activity of berberine-benzothiazole derivatives on the viral neuraminidase activity. Moreover, we tend to give many recently outfitted berberine derivatives that discovered potent anti-influenza activity via NA inhibition mechanism and examined by in vitro and in silico analysis. Notably, the past study indicated the role of berberine scaffolds mediated NA inhibition on the flu infection, which is determined by the NA inhibition assay and molecular docking measurements [14,15].

Furthermore, the NA inhibition assay was executed to determine the BBDs NA inhibition activity as shown in Figure 1. NA inhibition activity of BBDs was compared with standard NA inhibitor as oseltamivir. In the result, oseltamivir led between examined compounds along with NA activity was registered as $39.1 \%$ at $0.1 \mu \mathrm{g} / \mathrm{mL}, 29.1 \%$ at $1 \mu \mathrm{g} / \mathrm{mL}$, and $18.3 \%$ at $10 \mu \mathrm{g} / \mathrm{mL}$, respectively. On the other hand, NA activity among the analyzed BBDs, BBD7 was determined as the highest inhibition activity as dose-dependently on viral NA and are observed as $37.4 \%$ at $0.1 \mu \mathrm{g} / \mathrm{mL}, 32.1 \%$ at $1 \mu \mathrm{g} / \mathrm{mL}$, and $14.5 \%$ at $10 \mu \mathrm{g} / \mathrm{mL}$, respectively. An analogue BBD1 $(40.3 \%$ at $0.1 \mu \mathrm{g} / \mathrm{mL}, 30.4 \%$ at $1 \mu \mathrm{g} / \mathrm{mL}, 15.6 \%$ at $10 \mu \mathrm{g} / \mathrm{mL})$ and BBD11 (40.8\% at $0.1 \mu \mathrm{g} / \mathrm{mL}, 33.2 \%$ at $1 \mu \mathrm{g} / \mathrm{mL}$ and $18.4 \%$ at $10 \mu \mathrm{g} / \mathrm{mL})$ also displayed similar NA inhibition activity as oseltamivir. An analogues BBD4 and BBD5 showed moderate NA inhibition activity. This study's outcomes indicated that the synthetic transform in the berberine molecule effectively provides alternative methods against influenza virus infections, and it can be applicable for another infectious respiratory disease such as COVID-19. 


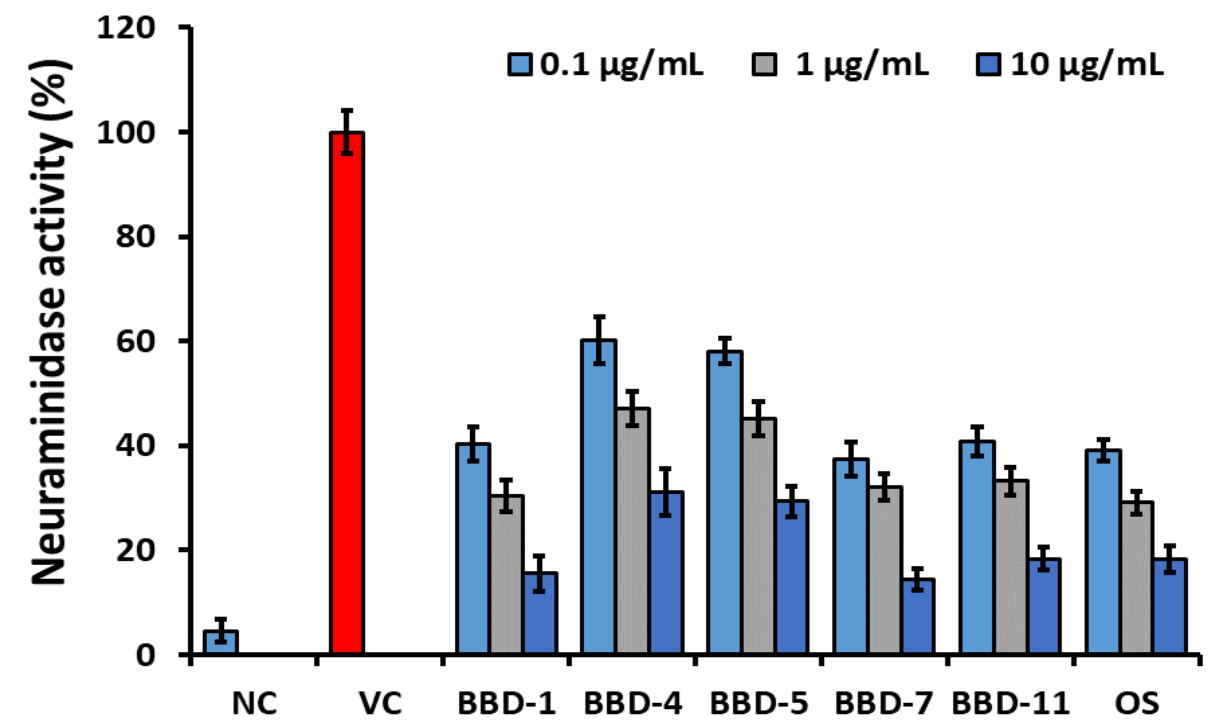

Figure 1. Neuraminidase activity of berberine derivatives comparing with oseltamivir. NC: Negative control. VC: Virus control. OS: Oseltamivir. The error bars are the mean of standard deviation in triplicate.

\subsection{Molecular Interaction between BBD and NA Protein}

Protein-ligand interactions developed by molecular docking are the primary factor in identifying therapeutically essential structure-based enzyme inhibitor design [24]. To find out the interaction between BBDs and the active sites of NA, in silico molecular docking research was executed by using the AutoDock Vina program (Figure 2, Table 2, Table S1, PDB IDs: 4WA4).

Table 2. Binding energies of the BBD-7 compared with oseltamivir on NA along with their Root Mean Square Distance value.

\begin{tabular}{|c|c|c|c|c|c|c|}
\hline \multirow{2}{*}{ \# } & \multicolumn{2}{|c|}{ Affinity (kcal/mol) ${ }^{@}$} & \multicolumn{2}{|c|}{ RMSD L.B \# } & \multicolumn{2}{|c|}{ RMSD U.B * } \\
\hline & BBD-7 & Ose & BBD-7 & Ose & BBD-7 & Ose \\
\hline 1 & -8.4 & -6.1 & 0 & 0 & 0 & 0 \\
\hline 2 & -8.1 & -6.0 & 5.706 & 2.205 & 9.555 & 4.419 \\
\hline 3 & -8 & -5.7 & 2.454 & 2.120 & 3.43 & 3.267 \\
\hline 4 & -7.9 & -5.6 & 7.43 & 2.362 & 11.301 & 4.659 \\
\hline 5 & -7.6 & -5.5 & 11.979 & 2.383 & 17.015 & 4.191 \\
\hline 6 & -7.6 & -5.3 & 12.165 & 2.376 & 16.089 & 4.982 \\
\hline 7 & -7.5 & -5.2 & 5.553 & 2.631 & 10.121 & 5.237 \\
\hline 8 & -7.4 & -5.2 & 16.288 & 2.645 & 19.921 & 3.757 \\
\hline 9 & -7.4 & -5.2 & 16.355 & 14.54 & 19.467 & 16.635 \\
\hline
\end{tabular}

(ब) Binding energies between ligand and receptor (Affinity (kcal/mol)). " RMSD L.B: Distance from best mode root-mean-square deviation lower bound. * RMSD U.B: Distance from best mode root-mean-square deviation upper bound. Ose: Oseltamivir.

There were nine best various poses and scores of BBDs discovered around the active site of influenza NA to compare with previously reported oseltamivir [18,19]. Among all the compounds, we conducted molecular docking of BBD1, BBD7, and BBD11 onto the NA crystal structure to know their neuraminidase inhibition. Figure 3 confirmed the docking poses of the BBD1, BBD7, and BBD11 ligands, and more significant binding activities were noticed as $-7.9 \mathrm{kcal} / \mathrm{mol},-8.4 \mathrm{kcal} / \mathrm{mol},-8.0 \mathrm{kcal} / \mathrm{mol}$, respectively, which is much better in comparison to oseltamivir $(-6.1 \mathrm{kcal} / \mathrm{mol})$. Besides, the ligand interaction between the BBDs and NA protein was determined by Maestro (Schrödinger, 2018) (Figure 3 and Table 3). 


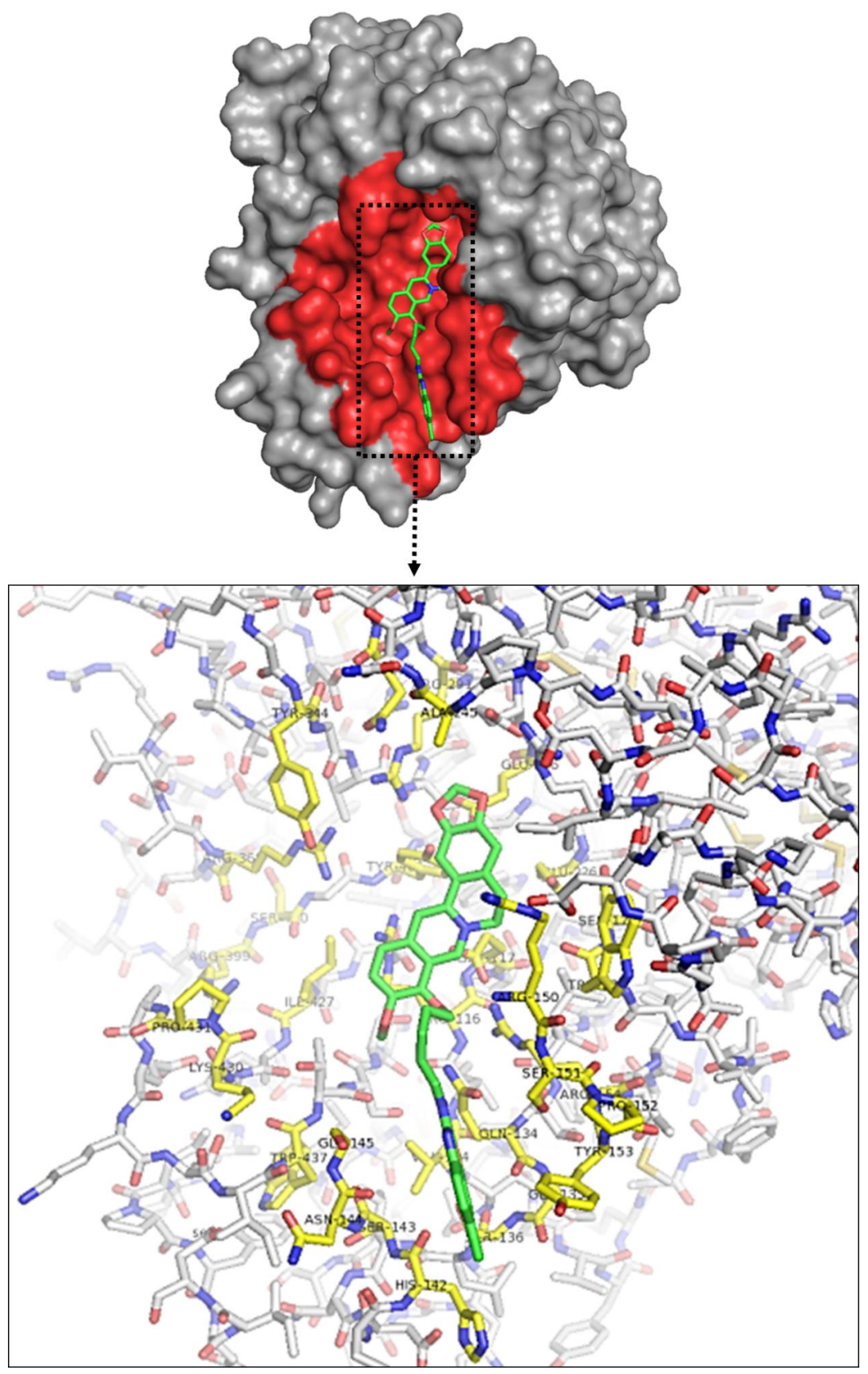

Figure 2. Crystal structure of influenza NA glycoprotein subunit docked with BBD-7. Pocked and important residues of influenza NA glycoprotein subunit colored as pink. 


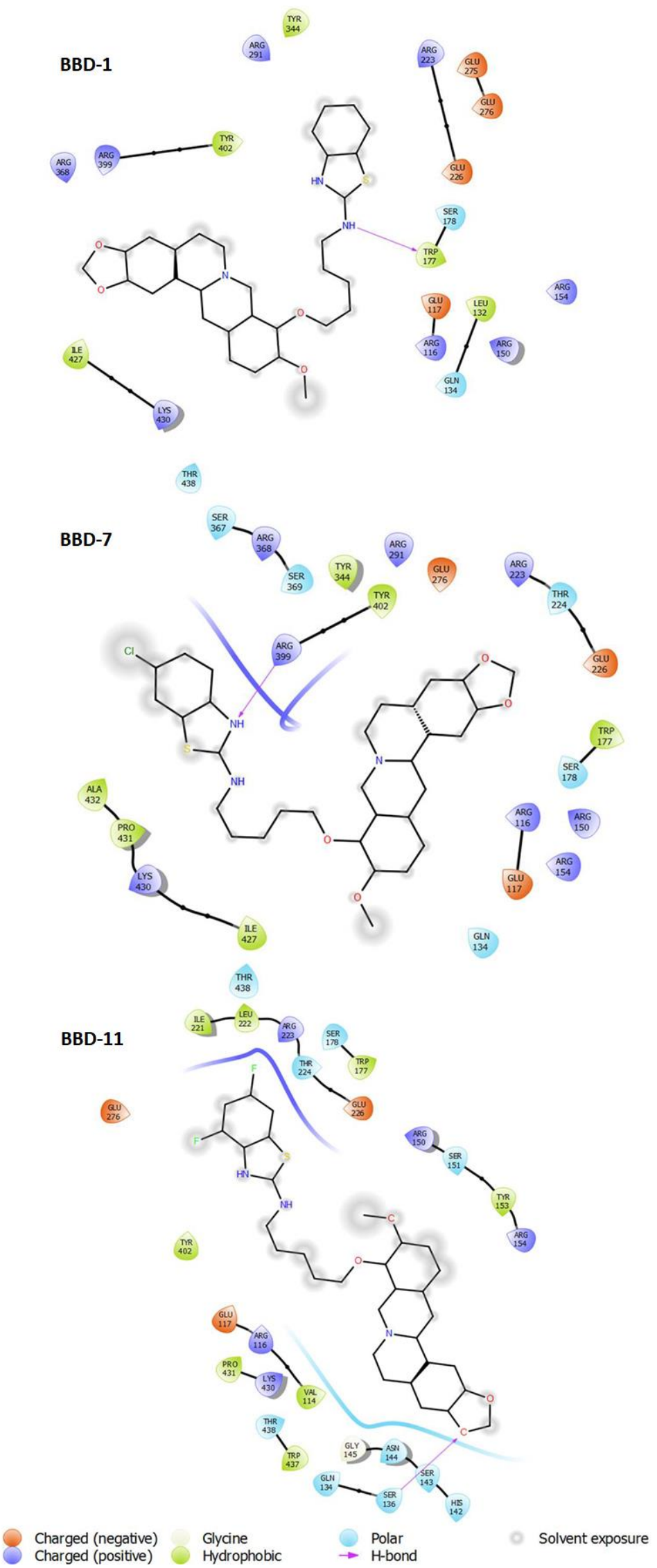

Figure 3. Overall binding interactions of BBD-1, BBD-7 and, BBD-11 were calculated in five Angstrom distances from the influenza NA subunit (4WA4). The ligand is represented in the best-scored pose. 
Table 3. The binding interaction residues registered between NA and compounds (distance five Angstroms).

\begin{tabular}{cc}
\hline Compounds & Residues \\
\hline Oseltamivir & ARG116, ARG150, ARG368, ARG291, GLU276 \\
& ARG291, TYR344, TYR402, ARG399, ARG368, \\
BBD-1 & ILE427, LYS430, THR438, ARG223, GLU275, \\
& GLU276, GLU226, SER178, TRP177, GLU117, \\
& ARG116, LEU132, GLN134, ARG150, ARG154 \\
& SER367, ARG368, SER369, ARG399, TYR344, \\
BBD-7 & TYR402, ARG291, GLU276, ARG223, THR224, \\
& GLU226, TRP177, SER178, ARG150, ARG154, \\
& ARG116, GLU117, GLN134, ALA432, PRO431, \\
& LYS430, ILE427, THR438 \\
& ILE221, LEU222, ARG223, THR224, SER178, \\
BBD-11 & TRP177, GLU226, ARG150, SER151, TYR153, \\
& ARG154, GLU276, TYR402, GLU117, ARG116, \\
& PRO431, LYS430, THR438, TRP437, GLN134, \\
& GLY145, ASN144, SER143, SER136, HIS142 \\
\hline
\end{tabular}

The BBD1 contain amino acid residues as ARG291, TYR344, TYR402, ARG399, ARG368, ILE427, LYS430, THR438, ARG223, GLU275, GLU276, GLU226, SER178, TRP177, GLU117, ARG116, LEU132, GLN134, ARG150, ARG154, and BBD7 contain amino acid residues as SER367, ARG368, SER369, ARG399, TYR344, TYR402, ARG291, GLU276, ARG223, THR224, GLU226, TRP177, SER178, ARG150, ARG154, ARG116, GLU117, GLN134, ALA432, PRO431, LYS430, ILE427, THR438, and BBD11 contain amino acid residues as ILE221, LEU222, ARG223, THR224, SER178, TRP177, GLU226, ARG150, SER151, TYR153, ARG154, GLU276, TYR402, GLU117, ARG116, PRO431, LYS430, THR438, TRP437, GLN134, GLY145, ASN144, SER143, SER136, HIS142 while oseltamivir contains amino acid residues as ARG116, ARG150, ARG368, ARG291, GLU276 as previously reported [18,19].

Thus, we noticed that compounds BBD7 and BBD11 interact with active site residues, which suggest these ligands act selectively on the NA of the group and assist in tighter binding and improved activity.

\section{Materials and Methods}

\subsection{Chemicals or Compounds}

The experimental procedure of synthesis of berberine-benzothiazole derivatives (BBDs) was previously reported [25]. Berberine received from Sigma-Aldrich Co., Ltd., Shanghai, China. Dimethyl sulfoxide (DMSO 0.1\%, Sigma-Aldrich) was used to dissolve the berberine-benzothiazole and control compounds for the in vitro tests.

\subsection{Reagents, Cells, and Viruses}

Madin-Darby Canine Kidney (MDCK) cells were carried out in Dulbecco's Modified Eagle's Medium (DMEM) supplemented with antibiotics (1\% Penicillin, Gibco BRL, Grand Island, NY, USA) and 10\% (v/v) fetal bovine serum (FBS). The cells were monitored at $37^{\circ} \mathrm{C}$ in an incubator supplemented with $5 \% \mathrm{CO}_{2}$. Tamiflu (Oseltamivir phosphate, Sigma) was beneficial for antiviral control. Influenza A viruses (A/PR/8/34 (H1N1, VR-1469), A/Vic/3/75 (H3N2, VR-822)), and influenza B viruses (B/Lee/40 (VR-1535), B/Maryland/1/59 (VR-296)) were acquired from the American Type Tissue Culture Collection (ATCC, Gaithersburg, MD, USA). 


\subsection{Cytotoxicity}

An in vitro bioassay of antiviral activity of the berberine-benzothiazole (BBD1-BBD14) derivatives assessed by utilizing the sulforhodamine (SRB) technique to find out the cytopathic effect (CPE) affected by a viral infection, as recently reported $[15,16]$. Briefly, MDCK cells were cultured in a 96-well plate $\left(1.5 \times 10^{4} /\right.$ well $)$ and monitored for the time being in a humidified cell culture incubator at $37^{\circ} \mathrm{C}$ with $5 \%$ of $\mathrm{CO}_{2}$ supplement to allow attachment of the cells towards the wall of the 96-well plate. The final compounds stock solution was dissolved in DMSO and diluted with a DMEM medium to a suitable concentration. Then, phosphate buffer saline (PBS) was used to wash 96-well plates twice and then added final compounds at several concentrations $(0.1,1,10,100 \mu \mathrm{g} / \mathrm{mL})$ to the plated in triplicate and incubated. The cells were fixed and washed, then recolored with SRB for $5 \mathrm{~h}$ after $48 \mathrm{~h}$. The excess SRB stain was washed with $1 \%$ acetic acid, and the attached stain dissolved with tris-base $[14,15]$. The color intensity was measured by a SpectraMax Plus 348 microplate reader (Molecular Devices, USA) at $510 \mathrm{~nm}$.

\subsection{In vitro Antiviral Bioassay}

A stock solution of influenza A virus (A/PR/8/34, A/Vic/3/75) influenza B virus (B/Lee/40, and B/Maryland/1/59) were diluted with DMEM medium containing trypsinEDTA in serial dilutions followed by their $50 \%$ of tissue culture infective dose (TCID 50 ) and which is utilized for virus infection. Briefly, MDCK cells were seeded in the 96-well plate $\left(1.5 \times 10^{4}\right.$ /well $)$ overnight. The next day, the medium was removed and washed twice with PBS. Then, $90 \mu \mathrm{L}$ of virus suspension $\left(50 \mathrm{TCID}_{50}\right)$ and $10 \mu \mathrm{L}$ medium having different concentrations of BBDs and oseltamivir solution $(0.1,1,10,100 \mu \mathrm{g} / \mathrm{mL}))$ was added to $96-$ well plates for $48 \mathrm{~h}$. All the treatments were maintained in triplicate for all concentrations, and the medium without samples was used as a control. The medium was removed after $48 \mathrm{~h}$ and washed twice with PBS. Then, $100 \mu \mathrm{L}-20{ }^{\circ} \mathrm{C} 70 \%$ acetone was added. The 96-well plates were dried after removing acetone, and $100 \mu \mathrm{L}$ of SRB $(0.4 \mathrm{mg} / \mathrm{L})$ was added. The excess of SRB was washed with a $1 \%$ acetic acid solution 4 to 5 times and dried again. AxioVision software (Carl Zeiss, Germany) was used to record cell images and also allotted to see the morphology of the cells, and once this observation, the SRB strain was dissolved with $100 \mu \mathrm{L}$ of $10 \mathrm{mM}$ of Tris base. A SpectraMax Plus 348 microplate instrument (Molecular Devices, USA) was used to record spectrophotometric data at $510 \mathrm{~nm}$ to analyze the cytotoxic concentration of $50 \%\left(\mathrm{CC}_{50}\right)$, inhibition concentration of $50 \%\left(\mathrm{IC}_{50}\right)$, and therapeutic indices (TI) $[14,15]$.

\subsection{Viral Neuraminidase Inhibition Assay}

A standard fluorimetric assay was done to decide the impact of BBDs on the influenza virus neuraminidase activity (NA) by using the standard method with minor modification as reported $[14,15]$. NA inhibition activity was carried out by using NA-Star ${ }^{\circledR}$ Influenza NA Inhibitor Resistance Detection Kit (Applied Biosystems, MA, USA). Briefly, NA assay was performed by making the reaction mixture containing an acetate buffer with influenza $\mathrm{A} / \mathrm{PR} / 8 / 34$ virus strain, tested compounds (at concentrations $0.1,1,10,100 \mu \mathrm{g} / \mathrm{mL}$ ), and a $50 \mu \mathrm{L}$ of NA-Star ${ }^{\circledR}$ were incubated at $37^{\circ} \mathrm{C}$ for $30 \mathrm{~min}$ at $5 \%$ of $\mathrm{CO}_{2}$. The reaction was started by adding $10 \mu \mathrm{L}$ of NA-Star ${ }^{\circledR}$ substrate and incubated at $37^{\circ} \mathrm{C}$ for $30 \mathrm{~min}$. The reaction was terminated by adding $60 \mu \mathrm{L}$ of NA-Star ${ }^{\circledR}$. The compounds' fluorescence intensity was measured by using the SpectraMax L luminescent microplate reader (Molecular Device, CA, USA).

NA activity $(\%)=($ Treatment/Virus $) \times 100$.

Treatment: Virus + Compound

Virus: Virus 


\subsection{Molecular Docking Study}

The AutoDock Vina program (Version 1.1.2, available at http://vina.scripps.edu accessed on 15 February 2021) used to perform in Silico molecular docking of BBDs towards influenza viral neuraminidase [26]. The Protein Data Bank (PDB, http:/ / www.rcsb.org/ pdb accessed on 15 February 2021) was used to find the crystal structures of the receptor (PDB IDs: 4WA4). The AutoDock-MGLTools (Version 1.5.6, http:/ / mgltools.scripps.edu accessed on 15 February 2021) program was used for further receptor preparation [14,15]. The water molecules and heteroatoms were deleted from the protein. For the NA model, Kollman charges and all the polar hydrogen atoms were added and file as saved to a pdbqt file. BBDs and oseltamivir were docked after covering the catalytic site of NA with a grid box of $52(\mathrm{x}) \times 52(\mathrm{y}) \times 48(\mathrm{z})$, grid points being separated by $0.375 \AA$ and centered at $-2.6(\mathrm{x}) \times-5.06(\mathrm{y}) \times 13.6(\mathrm{z})$. The other parameters were carried out at their default settings. The outcomes were assessed by analyzing the ligand-protein interactions, the free energy of binding, and the RMSD values. All the docked structures of BPDs-enzyme complexes were imagined by applying for PyMol programs (Version 1.8.2, Schrodinger

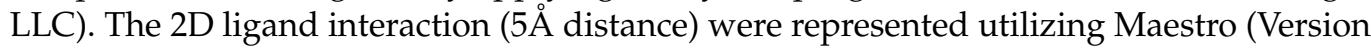
11.5.010, Schrodinger LLC).

\section{Conclusions}

In conclusion, a series of berberine-benzothiazole derivatives were discovered to be a new class of potential anti-influenza agents, and a total of 14 novel compounds were screened for the improvement of antiviral agents. The bio-assay results confirmed that the compounds BBD1-BBD14 exhibited exceptional antiviral activities towards influenza $\mathrm{A}$ and $\mathrm{B}$ virus strains, for example, A/PR/8/34, A/Vic/3/75, B/Lee/40, and B/Maryland/1/59 in cultured MDCK cells using oseltamivir as a controlled drug, among which compounds BBD1, BBD4, BBD5, BBD7, and BBD11 displayed outstanding antiviral activities. Furthermore, these compounds' neuraminidase inhibitory activities (BBD1, BBD4, BBD5, BBD7, and BBD11) exhibited comparable NA activity than control oseltamivir drugs. Additionally, in silico research proposed that the compounds BBD1, BBD4, BBD5, BBD7, and BBD11 may create an inhibitory effect on the NA of influenza viruses because of attachment of ligand and NA active site residues and highest binding energy. Our results revealed that berberine-benzothiazole derivatives could show potent NA inhibitory activity. Its discovery could be utilized to develop novel influenza NA inhibitors.

Supplementary Materials: The following are available online at https:/ / www.mdpi.com/1422-006 $7 / 22 / 5 / 2368 / s 1$.

Author Contributions: B.M.M. designed and supervised the study; M.K., G.E. and B.M.M. did experiment; M.K. and B.M.M. wrote manuscript; M.K. and B.M.M. aquires funding; S.-M.C., R.V.P. and H.-S.S. provides valuable inputs to this study. All authors have read and agreed to the published version of the manuscript.

Funding: This research received no external funding.

Institutional Review Board Statement: Not applicable.

Informed Consent Statement: Not applicable.

Data Availability Statement: Data is contained within the article or supplementary material.

Acknowledgments: This work was supported by the Dongguk University Research Fund 2020-2021.

Conflicts of Interest: The authors declare there are no conflicts of interest.

\section{References}

1. Zambon, M.C. The pathogenesis of influenza in humans. Rev. Med. Virol. 2001, 11, 227-241. [CrossRef]

2. World Health Organisation. Fact Sheet No. 211, Influenza. 2009. Available online: http://www.who.int/mediacentre/factsheets/ fs211/en/ (accessed on 29 January 2021). 
3. World Health Organisation. Cumulative Number of Confirmed Human Cases for Avian Influenza A (H5N1) Reported to WHO, 2003-2013; World Health Organization: Geneva, Switzerland, 2013; pp. 1-2.

4. Patel, M.; Dennis, A.; Flutter, C.; Khan, Z. Pandemic (H1N1) 2009 influenza. Br. J. Anaesth. 2010, 104, 128-142. [CrossRef]

5. Fajardo-Dolci, G.; Gutierrez-Vega, R.; Arboleya-Casanova, H.; Villalobos, A.; Wilson, K.S.; García, S.G.; Sotelo, J.; Villalobos, J.A.C.; Díaz-Olavarrieta, C. Clinical characteristics of fatalities due to influenza A (H1N1) virus in Mexico. Thorax 2010, 65, 505-509. [CrossRef]

6. Carrat, F.; Flahault, A. Influenza vaccine: The challenge of antigenic drift. Vaccine 2007, 25, 6852-6862. [CrossRef] [PubMed]

7. World Health Organisation. Available online: http:/ / www.who.int/news-room/fact-sheets/detail/influenza-(seasonal) (accessed on 29 January 2021).

8. Wagner, R.; Matrosovich, M.; Klenk, H.D. Functional balance between haemagglutinin and neuraminidase in influenza virus infections. Rev. Med. Virol. 2002, 12, 159-166. [CrossRef] [PubMed]

9. Varghese, J.N.; Laver, W.G.; Colman, P.M. Structure of the influenza virus glycoprotein antigen neuraminidase at $2.9 \AA$ resolution. Nature 1983, 303, 35-40. [CrossRef]

10. Gong, J.; Xu, W.; Zhang, J. Structure and functions of influenza virus neuraminidase. Curr. Med. Chem. 2007, 14, 113-122. [CrossRef]

11. Shen, Z.; Lou, K.; Wang, W. New small-molecule drug design strategies for fighting resistant influenza A. Acta Pharm. Sin. B 2015, 5, 419-430. [CrossRef]

12. Shen, X.; Zhang, X.; Liu, S. Novel hemagglutinin-based influenza virus inhibitors. J. Thorac. Dis. 2013, 5 (Suppl. S2), S149-S159. [PubMed]

13. Shin, H.B.; Choi, M.S.; Yi, C.M.; Lee, J.; Kim, N.J.; Inn, K.S. Inhibition of respiratory syncytial virus replication and virus-induced p38 kinase activity by berberine. Int. Immunopharmacol. 2015, 27, 65-68. [CrossRef]

14. Song, S.; Qiu, M.; Chu, Y.; Chen, D.; Wang, X.; Su, A.; Wu, Z. Down regulation of cellular c-Jun N-terminal protein kinase and NF-kappa B activation by berberine may result in inhibition of herpes simplex virus replication. Antimicrob. Agents Chemother. 2014, 58, 5068-5078. [CrossRef]

15. Gansukh, E.; Pandurangan, M.; Kim, D.H.; Mistry, B.M. Discovery of berberine based derivatives as anti-influenza agent through blocking of neuraminidase. Bioorg. Med. Chem. 2017, 25, 5185-5193.

16. Gansukh, E.; Kim, D.H.; Gyun, S.P.; Pandurangan, M.; Daniel, A.N.; Moon, S.H.; Kadam, A.A.; Patel, R.V.; Shin, H.S.; Mistry, B.M. Berberine-piperazine conjugates as potent influenza neuraminidase blocker. Int. J. Biol. Macromol. 2018, 119, $1204-1210$.

17. Rabbani, G.H. Mechanism and treatment of diarrhoea due to vibrio cholerae and Escherichia coli: Roles of drugs and prostaglandins. Dan. Med. Bull. 1996, 43, 173-185.

18. Chun, Y.T.; Yip, T.T.; Lau, K.L.; Kong, Y.C.; Sankawa, U. A biochemical study on the hypotensive effect of berberine in rats. Gen. Pharmacol. 1979, 10, 177-182. [CrossRef]

19. Peng, L.; Kang, S.; Yin, Z.; Jia, R.; Song, X.; Li, L.; Li, Z.; Zou, Y.; Liang, X.; He, C.; et al. Antibacterial activity and mechanism of berberine against Streptococcus agalactiae. Int. J. Clin. Exp. Pathol. 2015, 8, 5217-5223.

20. Liu, Q.; Xu, X.; Zhao, M.; Wei, Z.; Li, X.; Zhang, X.; Liu, Z.; Gong, Y.; Shao, C. Berberine induces senescence of human glioblastoma cells by downregulating the EGFR-MEK-ERK signaling pathway. Mol. Cancer Ther. 2015, 14, 355-363. [CrossRef] [PubMed]

21. Fan, X.; Wang, J.; Hou, J.; Lin, C.; Bensoussan, A.; Chang, D.; Liu, J.; Wang, B. Berberine alleviates ox-LDL induced inflammatory factors by up-regulation of autophagy via AMPK/mTOR signaling pathway. J. Transl. Med. 2015, 13, 92. [CrossRef]

22. Gansukh, E.; Muthu, M.; Paul, D.; Ethiraj, G.; Chun, S.; Gopal, J. Nature nominee quercetin's anti-influenza combat strategyDemonstrations and remonstrations. Rev. Med. Virol. 2017, 27, e1930. [CrossRef] [PubMed]

23. Gansukh, E.; Anthonydhason, V.; Jung, S.; Kim, D.H.; Muthu, M.; Gopal, J.; Chun, S. Nanotherapeutic Anti-influenza Solutions: Current Knowledge and Future Challenges. J. Clust. Sci. 2018, 29, 933-941. [CrossRef]

24. Xu, X.; Zhu, X.; Dwek, R.A.; Stevens, J.; Wilson, I.A. Structural characterization of the 1918 influenza virus H1N1 neuraminidase. J. Virol. 2008, 82, 10493-10501. [CrossRef] [PubMed]

25. Mistry, B.M.; Patel, R.V.; Keum, Y.S.; Kim, D.H. Evaluation of the biological potencies of newly synthesized berberine derivatives bearing benzothiazole moieties with substituted functionalities. J. Saudi Chem. Soc. 2017, 21, 210-219. [CrossRef]

26. Trott, O.; Olson, A.J. Software news and update AutoDock Vina: Improving the speed and accuracy of docking with a new scoring function, efficient optimization, and multithreading. J. Comput. Chem. 2010, 31, 455-461. [PubMed] 